REVISTA ANDALUZA DE ANTROPOLOGÍA.

NÚMERO 8: TURISMO DE BASE LOCAL EN LA GLOBALIZACIÓN

MARZO DE 2015

ISSN 2174-6796

[pp. 19-44]

http://dx.doi.org/10.12795/RAA.2015.i08.02

Fecha de Recepción: 27-12-2014

Fecha de Aceptación: 13-02-2015

\title{
TURISMO DE BASE LOCAL Y COMUNIDAD, ¿UNA VINCULACIÓN OPORTUNA?
}

\author{
Esteban Ruiz-Ballesteros \\ Universidad Pablo de Olavide (Sevilla)
}

\section{Resumen.}

El turismo de base local (TBL) surge como una estrategia para propiciar el desarrollo y la conservación ambiental en aras de una actividad turística sostenible; implica un modelo organizativo de la actividad turística centrado en el control local sobre la planificación, la gestión y los beneficios del turismo. Cómo se produce este control local es una de las piedras angulares tanto para su desarrollo práctico como para su estudio científico. Asociado a ese control local se hacen implícitas diferentes nociones de comunidad que pasan a formar parte constituyente del desarrollo del TBL. Pero ¿qué conceptualización de comunidad resulta operativa para el estudio del TBL?, ¿qué tipo de relación causal debemos esperar entre desarrollo del TBL y comunidad? Estas son las cuestiones que aborda el presente artículo al hilo de los resultados de diversos estudios etnográficos desarrollados en los últimos años en América Latina y España. Más allá de una conceptualización de la comunidad trazada desde ya clásicas perspectivas simbólicas o estructurales, se abogará por una noción procesual y práxica de la comunidad, anclada fuertemente a la capacidad de generar interacción social y acción colectiva en sociedades locales heterogéneas y que evidencian intereses en conflicto.

Palabras clave.

Turismo base local, comunidad, proceso, acción colectiva 


\begin{abstract}
.
Community based tourism (CBT) emerges as a strategy to promote local development and environmental conservation for the sake of a sustainable tourist activity. CBT implies an organizational model focused on local control over planning, management and the benefits of tourism. How this local control is produced becomes one of the cornerstones for its practical development and scientific study. Different notions of community are implicitly associated with 'local control', so community becomes a constituent part of the CBT. But, what concept of community is operational for studying CBT? What kind of causal relationship does exist between the development of CBT and community? These are the questions guiding this article in line with the results of various ethnographic studies carried out in recent years in Latin America and Spain. Beyond a conceptualization of the community drawn from traditional symbolic or structural perspectives, a processual and praxicalnotion of community will be proposed, strongly anchored to the ability to generate social interaction and collective action in heterogeneous local societies characterizefor internal conflicts of interest.
\end{abstract}

\title{
Keywords.
}

Community based tourism, community, process, collective action.

\section{INTRODUCCIÓN ${ }^{1}$}

Nociones como turismo comunitario, community-based tourism, ecoturismo comunitario, turismo rural comunitario...-que bien podrían encuadrarse en un concepto más amplio de turismo de base local (TBL) - , han ido surgiendo con fuerza en el ámbito del negocio, la promoción y la investigación turística. A pesar de la diversidad de situaciones a las que hacen referencia, todas estas nociones inciden —sin desconsiderar la sostenibilidad ambiental- sobre el protagonismo local en la planificación, el desarrollo, la gestión y los beneficios del turismo. Sin embargo,los contextos y tipologías que se recogen bajo este paraguas de turismo de base local son muy variados, respondiendo más bien a un continuum que va desde experiencias marcadamente colectivas de propiedad y gestión de los recursos y negocios turísticos a iniciativas de carácter familiar articuladas, en mayor o menor medida, a nivel local.

1. La investigación que sustenta este artículo ha sido desarrollada en el marco del proyecto "Retóricas de la naturaleza y turismo de base local: estrategias de sostenibilidad" (MINECO CSO2102-33044). En el trabajo de campo en Floreana participaron también Pedro Cantero y Javier Andrada; del equipo que llevó a cabo la etnografía sobre Alájar formaron parte junto al autor, Rafael Cáceres y Antonio L. Díaz. 
Bien es cierto que la antropología se caracteriza ante todo por su posición crítica ante el turismo, y razones hay de sobra para ello. Pero igualmente tenemos la responsabilidad, más allá de la crítica que hoy en día se ha vuelto obvia y poco aporta ya en el avance del conocimiento, de explorar alternativas de forma rigurosa. Pues igual que convenimos en que puede existir una agricultura más allá de la revolución verde, el turismo también puede desarrollarse según otras premisas y lógicas distintas a las hegemónicas. No son las actividades económicas en sí las que resultan perniciosas, sino la manera y la lógica en que se implementan.

A todas estas formas de turismo de base local, que procuran ser una alternativa, subyace una referencia, no siempre explícita, a la comunidad como principal agente de la actividad. Sin embargo, con bastante frecuencia y solo contadas excepciones (MatarritaCascante et al., 2010; Blackstock, 2005; Iorio \& Corsale, 2014; Ruiz-Ballesteros et al. 2008) las investigaciones en torno al TBL subestiman el referente comunidad, usándolo como sinónimo de sociedad local. En muchas ocasiones, de manera implícita, se trasluce una visión de comunidad como contexto social homogéneo y homogeneizante aplicado a sociedades locales campesinas o indígenas, a modo de contexto idílico y natural. En otras, se afirma explícitamente su carácter heterogéneo y los intereses divergentes de quienes habitan una misma localidad. Estas formas tan dispares de considerar la comunidad tienen importantes implicaciones a la hora de comprender apropiadamente qué es el TBL ya que lo que distingue a esta modalidad de organización turística es precisamente su connotación comunitaria: el control local sobre la actividad turística. Cómo se produce de facto este control local - cauces, alcance, dimensiones - es una de las piedras angulares tanto para su desarrollo práctico como para su estudio científico. En relación directa con ello, la conceptualización de comunidad —entendida como configuración particular de una sociedad local—resulta implícita a la propia noción de turismo de base local y como tal debería ser un concepto central para su estudio. Mas ¿qué comunidad?, ¿qué conceptualización de comunidad resulta operativa para el estudio del TBL?, ¿qué tipo de relación causal debemos esperar entre TBL y comunidad? Estas son las cuestiones que se abordarán en este artículo, ilustrado por tres estudios de caso muy dispares, conformantes de una línea de investigación que lejos de haber alcanzado todavía conclusiones sólidas, sigue su exploración etnográfica para alimentar consistentemente la reflexión teórica.

\section{DESDE LA COSTA ECUATORIANA}

La comuna Agua Blanca (300 habitantes, cantón Puerto López, provincia de Manabí, Ecuador) tiene su origen en una hacienda creada a principios del siglo XX, y en la que durante décadas se recolectó tagua, cultivó café y crió ganado (Ruiz-Ballesteros, 2009; Ruiz-Ballesteros y Gual, 2012). Los jornaleros que la habitaban quedaron desamparados 
por su bancarrota a finales de los años sesenta. La hacienda Agua Blanca se encontraba en un paraje de gran valor ecológico, compuesto por tres ecosistemas: el bosque seco tropical, el valle del río Buenavista, y el bosque nublado que se extiende hacia la montaña. Esta circunstancia llevó finalmente al estado ecuatoriano a expropiarla e integrarla en el Parque Nacional Machalilla (1979). Consecuentemente con el concepto de conservación esgrimido por la administración, los habitantes de la antigua hacienda deberían abandonar el lugar, para lo cual se llegó incluso a especular con unas tierras alternativas en el oriente amazónico.

Los aguablanquenses lucharon denodadamente por permanecer en el territorio que habitaban y centraron su supervivencia en actividades extractivas de gran impacto para la sostenibilidad del entorno: caza, extracción de madera, carboneo, venta ilegal de piezas arqueológicas. Con ello no se hizo más que agravar la supuesta incompatibilidad entre espacio protegido y presencia humana (Ruiz-Ballesteros, 2009).

La zona también era muy rica en restos arqueológicos de la cultura manteña (800$1450 \mathrm{dc}$ ) y a finales de los ochenta se iniciaron campañas de excavación que resultaron de importancia capital para el futuro. Los trabajos arqueológicos se llevaron a cabo a partir de un modelo de arqueología social y participativa que implicó muy activamente a los habitantes de la comuna en los trabajos de excavación, lo cual supuso tanto una fuente de empleo como un medio de sensibilización con el patrimonio. Pero, además, los arqueólogos se erigieron en mediadores del conflicto abierto entre los aguablanquenses y el parque (McEwan et al., 2006).

En esos momentos la zona experimentaba una profunda tensión, sustanciada en la persecución sistemática de las actividades básicas para la subsistencia de los aguablanquenses: carboneo, caza y extracción de madera. Este hostigamiento seguía teniendo como objetivo último rebajar al mínimo la presión humana en el territorio. Los comuneros, por su parte, se limitaban a reclamar sus derechos de ocupación y a subsistir con ayuda de la migración. Finalmente se atenuó el conflicto en tanto en cuanto ambas partes cedieron en sus pretensiones. El parque asumiría la presencia humana en el interior del espacio protegido a cambio de una profunda transformación en sus formas de vida y actividades extractivas. Los aguablanquensesse comprometían a desactivar progresivamente la extracción de recursos naturales a cambio de que les fuera permitido el cultivo y la ganadería de subsistencia,así como el desarrollo de un turismo de base local cuyos productos serían la naturaleza y la riqueza arqueológica del lugar. La comuna se hacía cargo del usufructo del territorio, incluida la gestión de sus restos arqueológicos, y se convertía de facto en su guardiana. Se configuró así un modelo multinivel de cogestión ambiental basado en una nueva conceptualización del territorio como bien común (Ruiz-Ballesteros y Gual, 2012), base para la gestión colectiva del turismo. 
Desde entonces Agua Blanca se ha convertido en uno de los modelos y referente del turismo comunitario en el Ecuador (Ruiz-Ballesteros y Solis, 2007). Valiéndose del potencial del Parque Nacional Machalilla, la localidad atrae cada año a casi un tercio de sus visitantes (en torno a 10.000 en 2008). Sus habitantes organizan, a partir de un comité e independientemente de operadores externos, la actividad turística local que consiste principalmente en un recorrido que muestra un pequeño museo, las ruinas arqueológicas, una laguna de agua sulfurosa y el bosque seco tropical. Esta actividad reúne a unas 30 familias de las aproximadamente 40 que componen el núcleo principal de la comuna (datos de 2009). Cada una de ellas aporta un guía que trabaja de forma rotatoria en turnos de atención a los turistas y en el mantenimiento de la infraestructura (restos arqueológicos, senderos, museo...). El aporte del turismo supone prácticamente la mitad de los ingresos monetarios de esas familias y asciende a un tercio del total ingresado por la comuna anualmente (Ruiz-Ballesteros, 2009; Ruiz-Ballesteros y Gual, 2012).

Desde el punto de vista organizativo dos son los factores fundamentales de este caso de estudio. En primer lugar, la emergencia de una capacidad de acción colectiva sostenida en el tiempo y que ha hecho posible el diseño de un producto, la consolidación de una infraestructura, y el desarrollo auto-organizado del negocio turístico. Aun considerando los distintos episodios de intervención externa, no cabe duda de que el liderazgo y la sostenibilidad del proceso de desarrollo del TBL se explican básicamente por razones endógenas.

En segundo lugar, toda esa acción colectiva ha estado marcada por una estrategia asamblearia y una lógica rotativa con el objetivo de tender a la igualdad de oportunidades dentro de la sociedad local (Ruiz-Ballesteros, 2012). Siendo el turismo una actividad profundamente mercantilizada y de objetivo exclusivamente monetario, sus lógicas organizativas y de funcionamiento interno en Agua Blanca hacen mayor hincapié en la lógica de la reciprocidad que en la del intercambio (Ruiz-Ballesteros, 2012). Los beneficios del turismo - provenientes de la recaudación de las entradas al recorrido guiado- se reparten de forma igualitaria entre todos los guías locales, aunque previamente se destina un porcentaje (en torno al 10\%) al funcionamiento de la comuna y el mantenimiento de la infraestructura turística, lo cual refuerza su carácter colectivo más allá de los participantes directos en el negocio turístico. Todo ello, incluido los turnos y organización del trabajo, se implementa desde una estructura de funcionamiento asambleario que reúne a todos los guías en un comité (Ruiz-Ballesteros, 2009). Asimismo se permite el desarrollo de iniciativas turísticas familiares (venta de artesanías, alojamientos, restauración...), que también se pueden coordinar colectivamente y devengan una parte de sus beneficios a la comuna. 
El objetivo del turismo en Agua Blanca no es exclusivamente económico sino también socio-ecológico: que la mayor parte posible de las familias locales puedan participar de él para minimizar sus actividades extractivas y el impacto de estas sobre el medio (RuizBallesteros y Gual, 2012); paralelamente se procura el acceso de los grupos domésticos al cultivo de subsistencia. Para lo primero se utiliza, como regulador, un umbral mínimo de ingreso que justifique la dedicación de los guías durante diez días al mes, en exclusiva, a la actividad turística (2009), en ese periodo no participaran de ninguna otra actividad. Es este umbral, en relación a los ingresos totales que se obtienen, el que marca el techo de personas que se pueden dedicar al turismo de forma sostenible para sus economías domésticas. Asimismo, ninguna familia podrá tener a dos miembros trabajando como guías mientras haya otras que no tengan ninguno. Para lo segundo, el cultivo de subsistencia, se pone a disposición de toda familia tierra y acceso al agua de riego.

Esta forma de organizar la actividad turística y la apuesta socio-ambiental que la subyace, se han convertido en referente para la organización y funcionamiento de la sociedad local. Los principios básicos que animan la organización del turismo a nivel local se han convertido en principios inmanentes al funcionamiento colectivo más general. A nadie se le escapa que la forma en que se gestionan los huertos (de titularidad colectiva pero uso familiar), el agua (cuya infraestructura y gestión es comunitaria) o cualquier nueva iniciativa local (acogida de voluntarios, planes de empleo) responde a la misma lógica instaurada desde los inicios de la actividad turística y antes desconocida en la vida local. Así la asamblea como foro de debate y espacio de decisión, donde se dirimen las frecuentes tensiones y conflictos de la vida local, y la rotación como forma de garantizar la igualdad de oportunidades para las familias e individuos, son los pilares de la vida colectiva (Ruiz-Ballesteros, 2009; 2012). Esto no significa que se eliminen las lógicas familiares e individuales, aunque sí se impide que se hagan exclusivas o hegemónicas en el funcionamiento social. Tampoco cabe pensarse la ausencia de problemas internos, sino más bien que la organización comunitaria establece la forma de dirimirlos. La base de este sistema reside en la apropiación común del territorio cuya posesión se entiende como colectiva, así todo uso familiar/individual del espacio (vivienda, agricultura, iniciativas económicas...) debe ser autorizado por la asamblea (Ruiz-Ballesteros, 2009; 2012). Como hemos visto, ese usufructo común sustenta una actividad turística cuyos productos son elementos consustanciales al territorio colectivo (ruinas arqueológicas, paisajes, laguna...) y cuyos beneficios repercuten proporcionalmente en la sociedad local. La forma en que se organiza la sociedad es inextricable de este modelo de apropiación colectiva. ¿Convendría usar la noción de comunidad para referirnos a esta sociedad local?, ¿en qué sentido?, ¿en qué medida el TBL contribuye al desarrollo de esta forma de organización local? 


\section{QUÉ COMUNIDAD PARA ENTENDER APROPIADAMENTE EL TBL}

La noción de comunidad es quizá una de las más controvertidas en las ciencias sociales. Anclada profundamente a una conceptualización heredera de los trabajos de Tönnies y Durkheim, se define tradicionalmente a partir de un conjunto de atributos, a saber: tamaño reducido, límites claramente trazados, homogeneidad interna, y autosuficiencia (Redfield, 1960:4). El agudo proceso de transformación social que afectó primero al mundo occidental y posteriormente al conjunto del planeta, disuelve en cierta medida sus clásicos cimientos estructurales, propiciando una conceptualización en la que primaría su carácter simbólico (Cohen, 1985) y su dimensión discursiva para organizar diferencias y similitudes sociales, por otra parte siempre interpretables. Con ello se certifica poco menos que la defunción operativa de la comunidad como noción de utilidad analítica, $\mathrm{o}$ en el mejor de los casos se mantiene residualmente a modo de epifenómeno simbólico. El cenit de su descrédito llega cuando se argumenta abiertamente que el concepto de comunidad enmascara la existencia de clases sociales, y que por tanto esa dimensión simbólica no es más que alienación.

Pero hay evidencias que cuestionan esta abolición drástica de la noción de comunidad. Frente a una abstracta sociedad, una gran parte de los humanos habitan un contexto social mucho más preciso y localizado sobre el que a pesar de la movilidad, conectividad y flexibilidad de sus vidas, desarrollan cierto sentido de totalidad. Por eso justo es reconocer a la comunidad una suerte de carácter "natural" para la existencia humana - "is the largest and most conmprehensive unit of society in the direct experience of the individual" (Wilkinson, 1991:71) - que se sustancia en el mundo de sus prácticas, representaciones y quehaceres cotidianos.

Sin embargo, es habitual que en referencia a cualquier contexto local de relación social se haya llegado a obviar el uso de la noción comunidad, para potenciar, en cambio, nociones vinculadas frecuentemente al capital social y humano (Brondisio et al., 2009). Este capital social está constituido por un agregado de atributos como la confianza, la reciprocidad, el compromiso o la equidad, entre otros. Paradójicamente, todos ellos nos recuerdan a los clásicos referentes de la comunidad, sólo que bajo nuevas nomenclaturas. Ahora no se habla de que un colectivo local constituya una comunidad, sino de que atesora capital social materializado en instituciones que nos ayudan a explicar analíticamente su capacidad (o no) de auto-organización y autogestión, en definitiva de acción colectiva.

Sostengo que esta negación de la comunidad para abrazar otras conceptualizaciones no supone siempre una ventaja y que no debemos renunciar a la capacidad heurística que nos ofrece un concepto de tanta raigambre; $y$ es que este nos permite entender el funcionamiento colectivo desde una perspectiva de totalidad antes que desde una fragmentación analítica de sus componentes en forma de atributos. No obstante, para ello es necesaria una re-conceptualización de la noción comunidad, que supere exclusivas 
acepciones estructurales o simbólicas. Resulta capital asumir que la comunidad se explicita de facto en procesos y prácticas cotidianas, cuya dimensión política y práxica resulta de mayor relevancia que la estructural o simbólica (aun incluyéndolas). Pero para comprenderla desde esta óptica habría que desarrollar una perspectiva mucho más compleja y flexible de la que habitualmente se pone en juego cuando se utiliza la noción de comunidad en el marco de las ciencias sociales.

La comunidad no es un estado de cosas a modo de la foto de un paisaje o una naturaleza muerta, más bien conviene entenderla de una manera marcadamente dinámica, en clave de proceso. Comunidad es un marco organizativo y de sentido con implicaciones múltiples. Se sustenta habitualmente en una trama de relaciones cara a cara que conforman una densa red social (en la que puede darse, según los contextos, una incidencia particular de los vínculos de parentesco pero que en ningún caso puede reducirse a ello). Entraña una forma de regulación política que toma cuerpo en distintas instituciones de autogobierno, incluyendo tanto acusados liderazgos internos como foros asamblearios. Heterogeneidad y desigualdad son norma antes que excepción, lo que alimenta el conflicto interno, propio de procesos de conjugación creativa de intereses particulares. En el seno de las comunidades se desarrollan formas de intercambio mercantil que conviven con una praxis de la reciprocidad, de la que no podemos olvidar en muchos casos las formas de trabajo y colaboración colectiva. Los humanos así articulados tienden a desarrollar una trama simbólica y de identificación en la que se encarna un profundo sentido del lugar y de lo común. Este - muy sucintamente esbozado- es el marco vital inmediato - o anhelado- de muchos seres humanos sobre el planeta, lo cual no quiere decir que al mismo tiempo no participen de otros marcos complementarios: la comunidad no es ni cerrada ni exclusiva.

Pudiera desprenderse de todo esto que la comunidad responde básicamente a "tener algo en común" pero desde mi punto de vista esta perspectiva simbólico-estructural impide apreciar lo más relevante del fenómeno comunitario: su clave no estriba tanto en "tener algo en común" como en "hacer en común". Comunidad es cuestión de prácticas. Claro que se tienen cosas en común, pero nos equivocamos si identificamos la comunidad exclusivamente con ello: la comunidad reside mucho más en la capacidad de hacer que en la de tener o compartir. La comunidad no es, se construye; y en este sentido presenta una doble articulación. Por un lado, es un marco para lidiar con la tensión interna entre lo individual y lo colectivo, propia a toda vida en común; por otro, cabe entenderla como un ejercicio táctico (de Certau, 1990) frente a otras instancias externas con voluntad de dominación (estado, mercado).

Desde una perspectiva pragmática la comunidad es un contexto de relación -entre humanos y de éstos con el medio- que adquiere sentido fenomenológico al anclarse a prácticas específicas entendidas como "actos en contexto" (Chaiklin y Lave, 1993), 
como "artes de hacer" que implican formas de comunicarse, organizarse, sentir y actuar colectivamente (de Certeau, 1990). Desde esta perspectiva resulta estéril la búsqueda de una esencia de la comunidad concebida como estructura; y asimismo banal quedarse en sus difusos límites simbólicos. Sólo el análisis de las prácticas - siempre dinámicas, cambiantes - alumbrará de manera consistente su funcionamiento real. La comunidad no existe sólo en la mente de sus miembros (Cohen, 1985) sino principalmente en el proceder de éstos, en su actuar. Asílo comunitario puede ser un marco de comportamiento (Cohen, 1985), factible en cualquier tipo de sociedad y cultura como expresión local de la misma. Estas prácticas conllevan un fundamento epistemológico (Bauman, 2001) para quienes participan de ellas; propician estrategias y tácticas colectivas (de Certau, 1990); y asimismo debiera entenderse como un antídoto creciente al individualismo hegemónico. La comunidad, como modelo de organización social, no responde solo a lo ancestral o lo tradicional, puede convertirse en un vector de innovación social: las comunidades se crean.

En gran medida, la base de este fundamento epistemológico reside en la práctica de la reciprocidad (Temple y Chabal, 1995; Temple, 2003a y 2003b; Godbout, 2013) que alimenta los lazos sociales y anima la integración social. La reciprocidad promueve lo común. Por su parte, el intercambio, como forma alternativa, supone una liberación de esos lazos sociales que patrocina la reciprocidad. El intercambio se concentra en los propios objetos que circulan (en vez de en los lazos sociales que éstos pudieran generar) y en las personas pero como individuos. Se anima así la acumulación antes que el don (Temple, 2003b). Reciprocidad e intercambio, como dos marcos de relación entre humanos y de éstos con el medio ambiente, dan lugar a dos lógicas económicas complementarias. Sin embargo, no cabe pensar que la comunidad sea el campo de la reciprocidad, ni situar fuera de ella el ámbito del intercambio. Esto sería una simplificación sin fundamento. Reciprocidad e intercambio conviven en tensión al interior de las comunidades (Temple, 2003b). No obstante, desde que se viene desarrollando como forma única de concebir las relaciones entre los humanos (alimentado por la globalización), el intercambio socava el espacio de la reciprocidad. La comunidad supera esa contradicción reciprocidad-intercambio a partir de interfases (Temple, 2003b) que permiten convertir marcos de intercambio en contextos de reciprocidad, evitando así la erosión completa de ésta. Parte de las prácticas comunitarias vienen precisamente a desarrollar esta función y es en ellas dónde hemos de encontrar la vigencia de la comunidad como expresión táctica (de Certau, 1990) que hace posible que el intercambio no se erija en referente único de la relación social (Temple, 2003a) propiciando la conformación de un ámbito propio de entendimiento común (Bauman, 2001). Estudiando los fenómenos comunitarios desde esta perspectiva podemos llegar a comprender cabalmente su vigencia y aporte en la globalización. No solo hablamos de comunidades "tradicionales", sino también de múltiples intentos para fundar nuevas comunidades en ámbitos urbanos o rurales, basadas en la agricultura, la 
manufactura o el turismo. Pero la comunidad tiene un alcance mayor, constituyendo no solo un contexto de articulación particular entre intercambio y reciprocidad, sino también un marco privilegiado de acción colectiva.

La sociedad local, convertida en comunidad,conforma un horizonte de funcionamiento colectivo en permanente tensión y conflicto, siempre en construcción: a "dynamic human system that remain viable through constant adaptive responses to change, and development of the ability to thrive in environments characterized by change" (Magis, 2010:403). Constituye un marco de relación inestable más que un estado adquirido; se evidencia en cada iniciativa y acción colectiva más que en unos determinados atributos. Las comunidades no están marcadas prioritariamente por el carácter intrínseco de sus miembros, los cuales de ningún modo son homogéneos (Agrawal y Gibson 1999), sino por la forma en que estos se relacionan entre sí en el contexto de un territorio.

Las prácticas que de aquí derivan tienen su expresión en los planos materiales y simbólicos de la existencia humana. La comunidad constituye un campo social en el que se expresa la interacción social emergente, generada por la capacidad (y necesidad) de los individuos de perseguir objetivos e intereses comunes (Wilkinson, 1991) a pesar o en paralelo a la existencia también de intereses y objetivos particulares.

Dentro de cualquier colectivo humano los intereses son variados, las capacidades de influencia individual distintas. Sus miembros se segmentan en virtud de objetivos particulares, diferentes entre sí y que los dividen. Evidentemente esta dinámica no engendra comunidad. La comunidad se desarrolla cuando, paralelamente, y sobre esos objetivos, intereses y grupos distintos, se comienza a tejer una articulación que los vincula a pesar de sus diferencias. Sin renunciar a esas diferencias puede configurarse una lógica común que convierte una gran parte de los objetivos e intereses más o menos particulares en asunto colectivo porque son así más fácilmente realizables. Se trata por tanto de un proceso de integración, que - repito- sin obviar diferencias, conflictos y particularidades, los hace converger aun en tensión permanente. La comunidad de la que hablo hace referencia a la propia acción, de ahí su carácter procesual e interaccional (Wilkinson, 1991); desde esta perspectiva, es una dinámica sostenida de acción colectiva.

El fenómeno comunitario implica personas (articuladas a menor escala en grupos de interés,grupos domésticos...) y recursos estratégicos para su funcionamiento (materiales, simbólicos, servicios) sobre un territorio. A partir del interés por dichos recursos se genera interacción en forma de acción colectiva (instituciones) la cual se sustenta necesaria y paralelamente en el desarrollo de formas de entendimiento y conocimiento compartidas. Liderazgos y grupos, recursos naturales y dinámicas sociales, intereses y acción, representaciones discursivas y prácticas, todos ellos son elementos protagonistas de los procesos de construcción de comunidad, en los que desde lo concreto se construyen "modos de proceder" colectivo. A mayor dinámica colectiva sobre intereses comunes, 
existencia de recursos colectivos y formas desarrolladas para su gestión, mayor índice de construcción comunitaria. Evidentemente este tipo de procesos no está libre de conflicto, de desigualdades, de intereses particulares, disputas, alienaciones, dominación material o simbólica. Desde el punto de vista analítico nos interesan sobre todo los procesos que permiten o bloquean la capacidad efectiva de acción común; solo si se alcanza un nivel estratégico de acción colectiva puede hablarse de comunidad: no toda sociedad local constituye una comunidad. La determinación de ese umbral estratégico es contextual y temporal, y tiene relación con la forma en que se configuran intereses colectivos respecto a los recursos básicos para el funcionamiento común. Es en este sentido que la comunidad es un proceso, un marco de interacción que se activa o desactiva, se potencia o bloquea, y que marca el tono de la acción colectiva, de la capacidad para actuar en sus contradicciones y tensiones-sobre asuntos comunes. Por supuesto,los niveles de igualdad o desigualdad interna de una sociedad local son factores capitales para el desarrollo de la interacción social y la acción colectiva. Asimismo, debe quedar claro que la comunidad no implica ausencia de tensión o conflicto, sino que se trata precisamente de un marco de interacción y prácticas para lidiar creativamente con esa tensión y conflicto inherentes, haciendo posible el desarrollo de acción colectiva.

Resumiendo, la comunidad se sustenta en prácticas que promueven de alguna manera la integración de lógicas de intercambio y de reciprocidad (Temple, 2003a y 2003b) lo que propicia un contexto socio-económico peculiar. A pesar de su inherente y consabida complejidad,heterogeneidad, conflictos y tensiones internas se desarrollan en su seno formas particulares de interacción social que alimentan la capacidad de acción colectiva (Wilkinson, 2001) sobre recursos y servicios estratégicos para la vida común. Con todo ello la comunidad se convierte en un potencial agente político - community agency (Magis, 2010)_que "increase the capacity of local people to unite, act and adapt to changing conditions" (Matarrita-Cascante et al., 2010: 738), fundamentalmente las provocadas desde el estado y el mercado. Desde esta perspectiva, la comunidad es una configuración social en potencia, conformada por prácticas y acciones colectivas que se activan o desactivan; un proceso siempre dinámico e inacabado (Ruiz-Ballesteros, 2012). Por tanto es el tono y el grado de la interacción social y sus consecuencias, lo que hace que una sociedad local tienda o no a desarrollar una configuración comunitaria que siempre será contextual y temporal.

Para el turismo de base local, en cualquiera de sus variantes, la localidad es su eje capital. Y no ya porque la actividad turística tenga lugar en un espacio localizado, sino porque su control por parte de la sociedad local es su característica distintiva. La forma e intensidad de este control es la medida del auténtico carácter local del turismo. Este control local puede presentar múltiples configuraciones, pero en cualquiera de los casos depende sustancialmente de la capacidad local de acción colectiva: de organizar de manera 
común la actividad turística. Asimismo, esta organización común de lo turístico, para que sea efectiva e implique consistentemente a una parte sustancial de la sociedad local, debe seguir una lógica que no se centre exclusivamente en el intercambio, sino que deje espacio también a la lógica de la reciprocidad. El turismo es un negocio mercantil al uso, mediado absolutamente por el intercambio monetario, pero su conversión en asunto colectivo al tiempo que individual requiere también para su sostenibilidad del desarrollo de la reciprocidad como lógica. El turismo de base local requiere de la localidad, pero no basta con la localidad, sino que esta debe desarrollar una configuración particular para que el turismo adquiera un carácter verdaderamente local: la localidad debe tender hacia una configuración comunitaria que según la conceptualización que aquí mantengo, se basaría por un lado en una potenciación de prácticas y lógicas recíprocas como antídoto a la exclusividad del intercambio, y por otro a la promoción de la interacción social y la acción colectiva para hacer de la actividad turística una actividad común (que trascienda incluso la propia esfera de lo meramente turístico). De esta forma TBL - como forma particular de organizar la actividad turística- y comunidad - como potencial tendencia organizativa de la sociedad local— son fenómenos estrechamente vinculados de manera recursiva.

Con frecuencia, el estudio del TBL se concentra en los aspectos explícitamente turísticos obviándose que la principal particularidad de este modelo no es el producto turístico que ofrece sino su contribución al desarrollo local; por tanto, tan importante como el carácter del turismo en el contexto local resulta comprender qué tipo de sociedad local se vincula a su desarrollo. Una localidad que implementa TBL debe estar al mismo tiempo desarrollándose como comunidad, y en la medida en que consiga lo uno alcanzará lo otro. El TBL parece estar ineluctablemente articulado al desarrollo como comunidad de la localidad en cuestión. Y si esta ya se conformara de alguna manera como comunidad, deberá comprobarse en qué medida su desarrollo turístico bloquea o cataliza esa expresión comunitaria de la sociedad local.

Es necesario, por tanto, acercarse de manera más precisa y explícita a la dinámica que se genera entre TBL y construcción de comunidad en aquellas sociedades locales que buscan implementar estrategias colectivas de desarrollo turístico. Agua Blanca nos ha ilustrado un proceso claro de convergencia entre TBL y construcción de comunidad; otros casos, más incipientes y menos evidentes, pueden ayudarnos a profundizar en esa conexión.

\section{DESDE LAS ISLAS GALÁPAGOS}

Floreana es la isla habitada más pequeña de las Galápagos (173 kmt², 160 habitantes). A pesar de que fue la primera isla del archipiélago en ser ocupada de forma permanente 
(1832), a principios del siglo XX quedó prácticamente deshabitada. En los años treinta se convirtió en destino de distintas familias de origen occidental que desencantadas con el mundo industrial del que procedían, vieron en ella la encarnación del paraíso natural, prístino y aislado (Ruiz-Ballesteros y Cantero, 2011). Paralelamente, colonos ecuatorianos comenzaron también a repoblarla. Hasta finales de los años setenta la población escasamente superó el medio centenar de habitantes. A partir de entonces experimentó una inmigración más sostenida y homogénea compuesta principalmente por familias ecuatorianas procedentes de la provincia de Loja lo que elevó su población hasta los aproximadamente 160 habitantes de 2014.

Los descendientes de los primeros colonos y los nuevos inmigrantes lojanos residen en una misma isla pero - expresado de una forma sucinta-habitan dos mundos distintos. Los primeros han mantenido una mentalidad propia del pionero, de lógica individualfamiliar y fuertemente competitiva, desarrollando un sentimiento de propiedad sobre la isla -que ellos entienden haber domeñado venciendo a la naturaleza inhóspita. Los segundos han traído hasta este remoto rincón del Pacifico un sentido de la familia extensa y la solidaridad propia de sus comunidades rurales de origen, en Loja, sólidamente marcadas por las redes de parentesco, la reciprocidad y la ayuda mutua. Son recién llegados pero han generado una profunda vinculación con la tierra que los acoge.

Floreana ha tenido siempre una posición periférica en el conjunto del archipiélago. Las políticas conservacionistas no se hicieron efectivas hasta principios de los ochenta. Antes de esa fecha la tierra podía ser libremente ocupada con la condición de que se cercara; pero cuando el parque nacional Galápagos hizo efectiva su presencia, se procedió a zonificar el conjunto de la isla, tomando en cuenta solo la tierra en posesión de los habitantes de esos momentos. Desde entonces no se puede ocupar más tierra y la actividad humana en la isla se limita a un escaso $2 \%$ de su superficie, repartido entre una zona urbana en la costa y otra de cultivo en la parte alta; el resto (98\%) es zona protegida sin uso humano. Este proceso conlleva un reparto desigual de la tierra entre los primitivos colonos (incluidos los primeros lojanos) y los que llegaron después de la zonificación del parque y ya no alcanzaron a apropiarse de tierra alguna. Esta circunstancia es causa de una profunda segmentación social que los lojanos han resuelto en gran medida con una práctica de cesiones gratuitas de tierra entre ellos (Andrada et al. e/p).

La vida en la isla ha adolecido de un profundo aislamiento, lo que unido a la estructural limitación de agua, supuso un duro régimen de autosuficiencia y subsistencia. Además, el desarrollo que la pesca, primero, y el turismo, después, tuvieron en el archipiélago, no afectó sustancialmente a la vida local (Andrada et al., 2010), muy centrada en esa agroganadería de subsistencia y en contactos limitados con el exterior. Las familias de los primeros colonos acentuaron progresivamente su apertura al exterior, participando 
del turismo y del desarrollo de la administración del archipiélago, mientras los recién llegados trabajaban como asalariados en sus fincas.

La situación fue cambiando cuando comenzó a desarrollarse el empleo público, por un lado, y el turismo de base local, por otro. El estado era poco presente en la isla, con excepciones como la escuela y el destacamento naval. El desarrollo de la administración local y de la presencia del parque nacional, han convertido al estado en un agente económico de primer orden que propicia 34 empleos (2013) en una localidad de 160 habitantes (Andrada et al. e/p). Por su parte, el turismo siempre estuvo presente en la isla pues esta ha sido destino privilegiado para los cruceros, pero estos no desembarcan donde se asienta la población sino en zonas deshabitadas; por tanto, la influencia económica de la actividad era nula, solo circunscrita al pequeño hotel que una de las familias pioneras regenta en la isla desde los años cincuenta. Sin embargo, la apertura de nuevas modalidades turísticas en el archipiélago —el turismo diario de puerto a puertosupuso un fuerte impacto para Floreana que a partir de 2006 comienza a recibir visitantes en un número sin precedentes. Estos tours visitan la isla durante apenas cinco horas, hacen un recorrido por las zonas históricas de la parte alta, almuerzan y regresan a Santa Cruz, la isla central del archipiélago. Este flujo ha provocado que se abran restaurantes, se dispongan de rancheras para el transporte de los turistas hacia la parte alta de la isla, se hayan preparado botes-taxi para el traslado desde las lanchas, e incluso se desarrolle un incipiente negocio local de artesanía (Andrada et al. e/p). En 2013 veintidós floreanos trabajaban ya en el sector turístico que recibía a más de veinte mil personas anualmente (2011 y 2012): hay días en que llegan más turistas que habitantes tiene la isla.

Con todo ello, el nivel de consumo y el estilo de vida han cambiado sustancialmente (Andrada et al e/p), lo que a su vez propicia cierta atenuación de las desigualdades sociales. El turismo que se ha desarrollado en la isla tiene un evidente carácter local, pero los niveles de integración colectiva del negocio son muy escasos. Si acaso podemos constatar la auto-organización de los transportes terrestres y marítimos, y asimismo la participación del gobierno local en el transporte y en la infraestructura para la venta artesanal, lo que propicia algunos ingresos colectivos; más allá de ello los negocios son de carácter familiar sin una coordinación explícita. De hecho, el turismo en la localidad es completamente dependiente del exterior, los tours se organizan y gestionan desde Santa Cruz; Floreana es un mero apéndice subsidiario de ese flujo que se genera sin control local alguno. La actividad turística ha ido creciendo de manera permanente pero su carácter y falta de control local ha hecho que los floreanos se cuestionen su papel en el negocio. Solo el $18,5 \%$ de los ingresos que propicia el turismo a la isla se queda en ella, son los tour operadores externos los que se benefician en mayor medida del destino Floreana. 
En vistas de ello, desde la sociedad local se ha propuesto transformar el modelo turístico, lo cual entraña una notable complejidad ya que implica tanto a actores externos que regulan la actividad (parque nacional, autoridades turísticas), como a la capacidad de acción colectiva local (para un tratamiento en profundidad ver Ruiz-Ballesteros y Brondizio, 2013, Andrada et al. e/p).

En una sociedad local de tan reducido tamaño, límites precisos y acusada tradición de autosuficiencia, parecería lógico el desarrollo de un funcionamiento comunitario. En nuestro trabajo de campo hemos constatado la existencia de múltiples contextos y prácticas de reciprocidad (trabajo, alimentos...), pero si bien existen un par de hitos de acción colectiva (los trabajos para traer el agua hasta el núcleo habitado o la construcción del cementerio), en general no puede afirmarse que la sociedad local haya funcionado habitualmente en clave comunidad:la desigualdad y polarización interna han bloqueado esta posibilidad. Sin embargo un evidente proceso de comunitarización ha comenzado a desarrollarse recientemente, ¿cuáles son sus claves?

En primer lugar, no podemos desconocer el cambio en las pautas de consumo y la forma de vida que a su vez ha propiciado que se limen en cierto sentido las agudas desigualdades sociales internas. La apertura de la economía local y la monetarización de esta a través del empleo público y los ingresos del turismo, han rebajado las distancias sociales al interior de la localidad. Por otra parte, las actividades económicas tradicionales (agricultura y ganadería) en poco animaban la acción colectiva, y si bien sí han propiciadola reciprocidad entre los habitantes de origen lojano no han catalizado ningún proceso colectivo notable. En principio el desarrollo del turismo no ha jugado un papel muy diferente. Sin embargo, la apuesta por un cambio en el modelo turístico hacia un "turismo comunitario", ha puesto en evidencia la necesidad de acción colectiva si se quiere realmente procurar un turismo más local que el actual, un modelo en el que el control y los beneficios locales se acrecienten. Para ello la estrategia es bien sencilla: ampliar el destino turístico, diseñando nuevos productos que propicien otra forma de visita la isla, y que principalmente anime la pernoctación, que en la actualidad es bien reducida y solo beneficia a un par de familias. No sin tensión y conflicto interno, la sociedad local está construyendo una alternativa que manteniendo los intereses familiares ya vigentes, genere un modelo colectivo que encauce el flujo turístico según intereses comunes. La clave y primer paso ha sido construir un nuevo producto con la connivencia del parque (que a su vez quiere limitar el flujo de visitantes en la isla y entiende que el control local le ayudaría a hacerlo); se trata de un sendero cuyo recorrido obligaría al visitante a pernoctar en Floreana y que ofrece distintos alicientes nuevos hasta ahora vedados a los visitantes de la modalidad puerto a puerto y solo disponibles para los exclusivos clientes de los cruceros.

En este caso, el recurso turístico ha sido literalmente construido por la población local. Con trabajo colectivo a modo de mingas, los fines de semana durante varios meses, una 
representación sin precedentes de la sociedad local (solo una familia de pioneros se ha autoexcluido del proceso) han reabierto un camino de siete kilómetros de indudable interés histórico y ambiental. Se ha constituido una empresa comunitaria local para gestionarlo y organizar una serie de servicios turísticos en torno a él (desde guías propios a actividades de campamento o acuáticas). Se entiende que la clientela de este producto turístico colectivo alimentará también los negocios familiares ya existentes (restaurantes, alojamiento...). Así, y de manera complementaria a otras modalidades turísticas, la localidad quiere erigirse en actor principal del turismo local. Todo este proceso no está exento de suspicacias, desconfianzas, críticas y reproches (en gran parte entre pioneros y lojanos), lo que ha puesto al descubierto los intensos factores de bloqueo ala acción colectiva y por ende al funcionamiento común dentro de esta "pequeña comunidad" (Ruiz-Ballesteros y Brondizio, 2013, Andrada et al e/p).

De una manera contraria al sentido común, la comunidad - como modelo de organización social - no tenía consistencia en Floreana, faltaba capacidad de acción colectiva por más que se diesen distintos atributos estructurales y simbólicos, y asimismo existiesen suficientes dosis de reciprocidad entre una buena parte de sus miembros. El desarrollo de una primera configuración del TBL — básicamente de corte familiar-no mejoró sustancialmente esta circunstancia. Solo cuando se ha procurado intensificar colectivamente el control local sobre la actividad turística aparecen trazos inequívocos de desarrollo de una configuración comunitaria, en sintonía con la generación de un turismo que tiene su base en un bien común (el nuevo sendero, que se ha asumido como poco menos que propiedad comunal), una nueva organización colectiva para gestionarlo, y el compromiso de generar beneficios colectivos que además de revertir sobre la infraestructura turística lo haga sobre el desarrollo agrícola y ganadero de la isla, punto de interés para una parte sustancial de sus habitantes no directamente vinculados al negocio turístico (Andrada et al e/p). Este proceso de pretendida intensificación del carácter local del turismo no puede desvincularse de una creciente estabilidad política local evidenciada en los procesos electorales del gobierno parroquial (con lista única en dos elecciones consecutivas), de un aumento de la significación de las instituciones y autoridades políticas locales, de la conformación de una asociación que articula a la totalidad de propietarios y cultivadores locales, ni de una potenciación simbólica creciente de lo local. Todo ello contribuye de manera inextricable y junto a la iniciativa turística comunitaria, a fomentar el sentido y la acción común, hasta hace muy poco escasamente evidenciada en la vida local.

La experiencia del TBL en Floreana alumbra en una primera fase una simple adaptación pasiva al mercado, y en una segunda - en paralelo a una potencial construcción de comunidad - una estrategia de control sobre el mercado turístico que empoderaría a la sociedad local frente al exterior. Queda por ver si el turismo, tal como comprobamos 
en Agua Blanca, se convierte en catalizador principal del desarrollo comunitario de la sociedad local o si toda la iniciativa queda en frustración, mostrando la incapacidad de acción colectiva.

\section{DESDE ANDALUCÍA}

No sería temerario afirmar que en Europa lo comunitario ha sido prácticamente arrasado por el Estado y su abrumadora presencia en la vida cotidiana; la acción colectiva es cooptada por instancias administrativas y las prácticas de reciprocidad severamente limitadas por la mercantilización de las relaciones sociales. Precisamente por eso resulta esclarecedor orientar también nuestro trabajo hacia contextos occidentales en los que situaciones más "hostiles" a modos comunitarios de funcionamiento social pueden suponer un serio bloqueo al desarrollo del TBL de forma consistente: esta dificultad estructural es un buen ámbito para contrastar nuestras ideas.

Alájar es una localidad de aproximadamente 800 habitantes, situada al norte de la Provincia de Huelva (Andalucía, España), dentro del Parque Natural Sierra de Aracena y Picos de Aroche. La transformación del mundo rural que afectó a España a mediados del siglo XX tuvo una especial incidencia en esta zona que llegó a los años ochenta sumida en un agudo proceso de deterioro ambiental, demográfico y económico que la convirtió en una comarca periférica a los ojos de la administración. No es de extrañar que sobre ella se focalizaran políticas públicas para la reactivación y el desarrollo, animadas notablemente desde las instituciones europeas con el objetivo de revertir la "situación marginal" de muchas zonas rurales. Este punto de inflexión inaugura la aplicación de una lógica que tiene varios ejes convergentes: la conservación ambiental (creación del parque natural en 1989), la patrimonialización cultural (declaración de conjuntos histórico-artísticos, bienes de interés cultural...), la promoción de productos locales (alimentos, artesanías) y el desarrollo del turismo (programas LEADER y PRODER desde 1994). La transformación ambiental, económica, demográfica y cultural ha sido notable y muestra hoy claramente sus efectos. El paralelismo con los casos anteriores es evidente, las políticas que en el "tercer mundo" han estado patrocinadas por ONGs y agencias internacionales de cooperación al desarrollo, aquí lo están por el Estado y la Unión Europea. En Alájar esta transformación tiene dos vectores básicos.

Por un lado, un notable desarrollo del turismo de base local (sibien la localidad ya tenía una tradición turística desde finales del siglo XIX) sustentado en la naturaleza y la ruralidad, y que se sustancia en productos específicos como el senderismo y la gastronomía. El perfil del turista es muy variado aunque indudablemente urbanita, y sus flujos van desde la visita puntual diaria durante el fin de semana a las estancias con pernoctación o el alquiler de viviendas por temporadas, lo que ha propiciado el desarrollo de un sector 
turístico local centrado principalmente en la restauración, el alojamiento (desde hoteles a casas en alquiler), y el comercio de productos locales y artesanías. Estas iniciativas tienen un profundo efecto en el conjunto de la economía local a través de los servicios indirectos que precisan.

Por otro lado, encontramos una peculiar evolución demográfica de la localidad. Desde finales de los setenta Alájar y sus aldeas se han erigido en un foco de atracción para personas que buscan formas de vida alternativa, configurándose un proceso que podemos encuadrar bajo las nociones de neoruralidad (Chevalier, 1981; Nogué, 1988) y, más ampliamente, amenity migration (Gosnell \& Abrams, 2011; Moss, 2006). Según nuestros propios cálculos, estos migrantes - extranjeros y nacionales-suponen algo más del $20 \%$ de la población local. A nadie puede escapársele el hecho de que además de una influencia cuantitativa, esta población tiene un extraordinario efecto cualitativo en la vida local a múltiples niveles, tanto positivos como negativos. Estos forasteros tienen un perfil bien distinto a los nativos del pueblo, sus ocupaciones son otras, hay escasa integración a nivel simbólico, y los conflictos emergen potencialmente como consecuencia de cosmovisiones divergentes.

Así, la renovación socio-demográfica y el desarrollo del TBL están conformando progresivamente una nueva sociedad en la que locales y forasteros residentes procuran un encaje en la vida cotidiana. Si seguimos nuestra noción de comunidad, Alájar muestra una gran capacidad de acción colectiva a nivel simbólico, en torno a las celebraciones y manifestaciones festivas que son organizadas desde la sociedad civil (sea por locales o forasteros separadamente); pero no así en cuanto al funcionamiento socio-económico que tiene un marcado carácter individual-familiar. Asimismo, la creciente dualización de la sociedad local (locales y forasteros) está explicitándose en la trama asociativa que evidencia claramente una separación de intereses. Si bien hay importantes espacios de sociabilidad (bares por ejemplo) frecuentados conjuntamente por locales y forasteros residentes, también hay contextos institucionales, como la escuela, en los que diferencias y conflictos afloran. A pesar de sus escasos 800 habitantes, Alájar es un contexto de creciente heterogeneidad y polarización social que dificulta el desarrollo de pautas y modos comunitarios: la comunidad, tal como la entendemos aquí, está por construirse. ¿Qué papel juega en todo esto el desarrollo del TBL?

Alájar presenta un desarrollo del sector turístico sin parangón en los pueblos del entorno, tanto en cantidad como en calidad de su oferta. En el gráfico adjunto podemos encontrar el número de iniciativas y su titularidad (locales y forasteros residentes). 


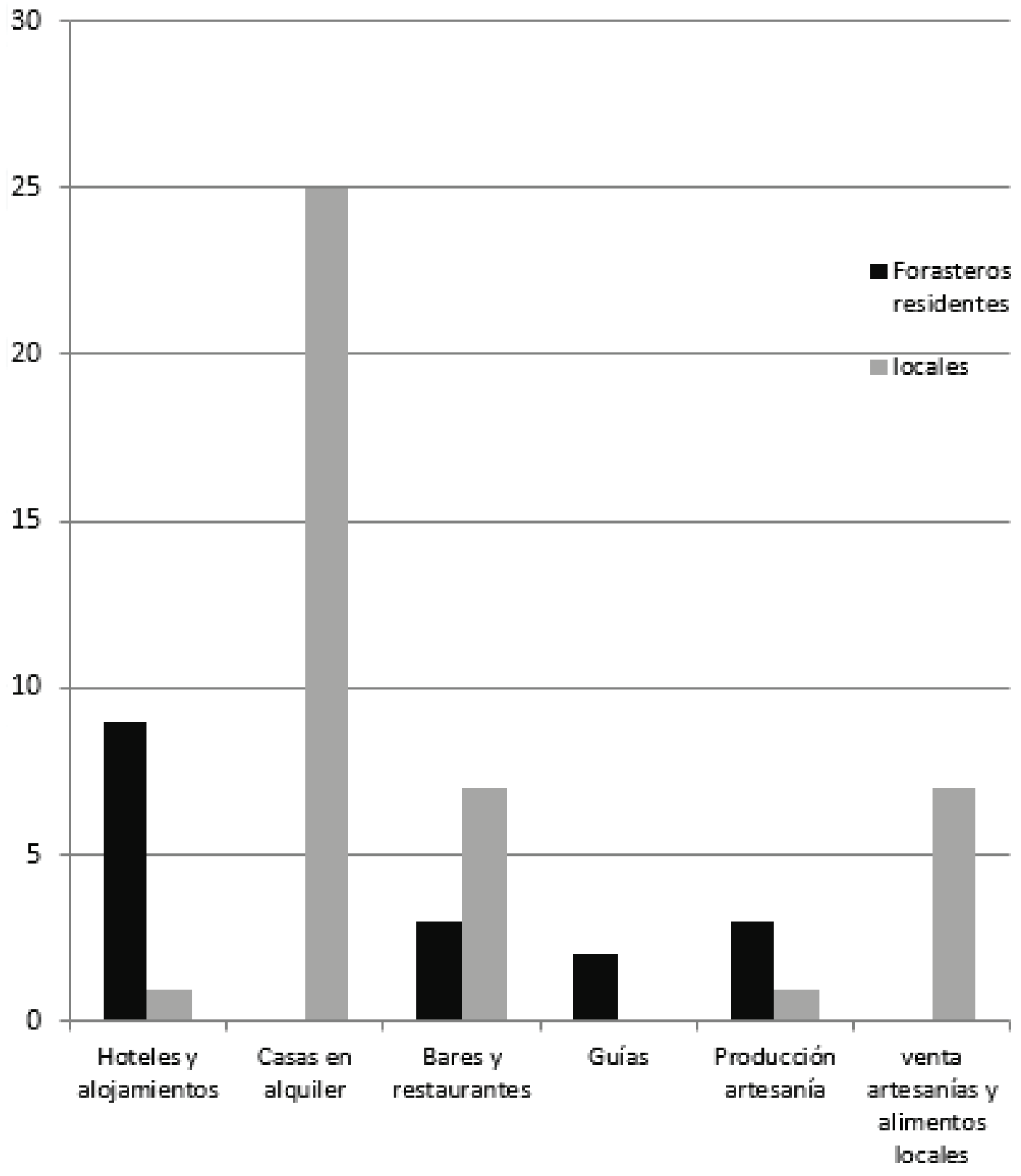

Ilustración 1.- Número de iniciativas turísticas en Alájar gestionadas por forasteros y locales

De manera general las iniciativas locales se concentran en actividades con las que los alajeños mantienen cierta familiaridad y requieren una inversión limitada (restaurantes, venta productos locales o casas para alquilar), mientras que los establecimientos hoteleros han supuesto una inversión importante y unas habilidades y conocimiento más cercanos a las capacidades de los forasteros. Estos han sido capaces de conectar la localidad con el exterior (clientes extranjeros), aumentar las pernoctaciones y atenuar la estacionalidad 
del destino. Todo ello ha contribuido a potenciar la clientela de la restauración y a propiciar el desarrollo de otros servicios turísticos (guías, ventas...). Así, la presencia de iniciativas lideradas por forasteros es capital para entender el desarrollo del TBL en el pueblo.

Sin embargo el TBL en Alájar - a pesar de su indudable carácter local: sus promotores son residentes y el empleo-suministro queda en gran parte circunscrito al pueblopresenta dos características que condicionan su sentido colectivo. Por un lado el sector y sus iniciativas tiene un carácter familiar y no hay un espacio formal para la articulación más allá de este nivel. Por otro, se reproduce en su seno la segmentación y polarización que afecta al conjunto de la sociedad local. ¿Debemos entonces entender que el TBL no contribuye en ninguna medida a un hipotético proceso de desarrollo de pautas comunitarias?, ¿invalidaría esto su presumido carácter de "base local"?

El negocio turístico a nivel local, además de la lógica competencia, comporta un alto grado de complementariedad interna. Las vinculaciones entre oferta gastronómica y hotelera son evidentes - a los propietarios de hotel les interesa una oferta de restauración lo más desarrollada y de calidad posible, lo que sería un aliciente para sus clientes; a los dueños de restaurantes les viene muy bien que cada vez más gente pernocte en el pueblo...así como la que pueda darse entre hoteles y servicios de guía, o entre restaurantes y proveedores de productos locales. Todos estos intereses particulares configuran un marco de relaciones personales que si bien tiene una base mercantil, también contiene claras trazas de reciprocidad, lo cual lo convierte en un contexto muy destacado de interacción social (una de las bases de los procesos de comunitarización). Son lugar común las recomendaciones de unos negocios respecto a otros, los suministros de unos a otros, en definitiva las vinculaciones personales que se establecen entre sus dueños y que sin duda trascienden el propio negocio. En un reciente estudio centrado en este tipo de conectividad (Ruiz-Ballesteros y Cáceres, e/r) hemos determinado que el 35\% de las relaciones detectadas en el contexto del TBL en Alájar están lideradas por locales y el 65\% por forasteros ${ }^{2}$. Asimismo, el $60 \%$ de esas relaciones se dan entre negocios propiedad de forasteros y negocios propiedad de locales; el $31 \%$ entre negocios de forasteros y el $8 \%$ entre negocios de locales. Asimismo, los dos negocios más intensamente conectados con el conjunto del sector - ejerciendo tanto centralidad como liderazgo dentro de él-

2. Este estudio de las relaciones entre los promotores turísticos locales se ha centrado en el análisis de tres formas de relación: (a) realización de actividades y oferta de productos conjuntos: ¿quién realiza actividades conjuntas con quién?, ¿quién oferta productos turísticos en común?, (b) recomendaciones y derivación habitual de clientes entre negocios: ¿quién recomienda a quién y deriva clientes a otros si no puede atenderlos?, y (c) suministros y servicios prestados directamente: ¿quién suministra servicios o productos a otros? Sobre 21 iniciativas turísticas locales, privadas y públicas, se han constatado 87 conexiones distintas, diferenciadas y contrastables, con las que se ha podido trazar una red de relaciones al interior del sector turístico local y cuantificar la conectividad del sector, sus nodos y agentes principales. 
resultan ser dos alojamientos regentados por forasteros. Estas relaciones, en principio de manifiesto sentido mercantil, propician inmediatamente un marco de reciprocidad que hemos podido comprobar nítidamente en nuestra investigación etnográfica: en un contexto tan reducido socialmente como Alájar, la vinculación mercantil se traduce en relación social y viceversa. Las principales conclusiones de esta exploración apuntan a: (a) la intensidad de las relaciones informales entre las familias vinculadas a la actividad turística, que diluye la polarización locales-forasteros y (b) el protagonismo de los emprendedores forasteros en la construcción de relaciones dentro del sector.

Más allá de los empleos y de los ingresos para la economía local —sin duda capitales para su funcionamiento, y más en momentos de crisis - esta aproximación interaccional al TBL nos muestra su efecto más social. En Alájar, una sociedad crecientemente polarizada entre locales y forasteros residentes, no existen actividades económicas en las que estos dos mundos se encuentren o tengan la necesidad de cooperar de manera intensa. Ni todos los forasteros, ni todos los locales, participan de la actividad turística, pero los que lo hacen muestran un notable nivel de conectividad (que puede traducirse en conflicto, obviamente, pero que constituye en sí interacción social). Si en un principio la segmentación de actividades dentro del sector turístico podría hacernos pensar en que el TBL agudiza la polarización social ya existente, el análisis micro nos muestra todo lo contrario: resulta ser un contexto de interacción e integración social (insisto: esto no quiere decir ausencia de conflicto), que mediante relaciones mercantiles - antesala de relaciones recíprocas: en una sociedad local de este tamaño es difícil conjugar solo la lógica del intercambio-, contribuyen a paliar la fractura que separa a estos dos mundos que conviven en el mismo pueblo. El TBL constituye hoy uno de los ámbitos de interacción creativa entre locales y forasteros residentes.

Lejos, sin embargo, queda todavía la configuración de un marco estable de acción colectiva. Existe una consciencia común clara de la oportunidad de generar un producto turístico local explícito, pero - curiosamente- la iniciativa promovida por el ayuntamiento para crear una asociación empresarial no ha tenido éxito. No obstante hay estrategias informales, aunque parciales, en este sentido.

Como vemos, el desarrollo del TBL en Alájar, analizado desde una perspectiva microsocial, apunta una incipiente emergencia de tendencias comunitarias, aun en una sociedad local teóricamente complicada para que ello pudiera darse. En Alájar el TBL lo es por la muy sencilla razón de que la oferta está patrocinada por población local y por el efecto local del empleo y los beneficios. Aumentar el carácter "local" de esta actividad turística pasa por un desarrollo más intenso de relaciones recíprocas y, sobre todo, por el desarrollo de acción colectiva en torno al turismo. Con ello también se estaría potenciando la emergencia de prácticas comunitarias.¿Es razonable hablar de incipiente construcción de comunidad a través del turismo? No parece que la semilla de 
lo comunitario haya germinado - como no lo ha hecho en Floreana hasta fechas muy recientes- pero sin duda el TBL sería uno de los pocos resquicios en este sentido dentro de esta sociedad local tan polarizada, subsumida por el Estado y cuya organización exclusivamente familiar facilita la hegemonía del mercado.

\section{CONSIDERACIONES}

Lo que presento aquí forma parte de unalínea de investigación en marcha. No cabe plantear una conclusión al uso, sino más bien avanzar en las reflexiones que van aquilatándose conforme se profundiza en los estudios de caso y se analizan sus resultados. En vistas de ello parece que la vinculación entre TBL y comunidad, tal como se desarrolla en estas páginas, puede resultar de interés para comprender apropiadamente el sentido y los límites del TBL. ¿En qué medida y por qué?

La amplitud del fenómeno que llamamos turismo de base local precisa de anclaje sólido a la noción de comunidad - ¿cómo si no dar consistencia a esa pretendida "base local"?-, al tiempo que esta noción requiere de una re-conceptualización que la adecúe a los procesos de globalización. El TBL no es un mero fenómeno económico, sino una apuesta por el desarrollo alternativo de la actividad turística que, a su vez, persigue la emergencia de sociedades locales distintas a las que producen las actividades económicas implementadas según la lógica hegemónica.

Esta confluencia del TBL - como apuesta social - con una noción procesual y práxica de comunidad - como herramienta analítica- nos permite desarrollar un marco de estudio que puede añadir factores de comprensión, comparación y evaluación para las experiencias de TBL. No se trata por supuesto de un marco ni definitivo ni exclusivo, sino complementario a otros que hagan hincapié en aspectos gerenciales, económicos, ambientales o patrimoniales de las experiencias del TBL. Y en este sentido hemos aplicado otros marcos analíticos a algunos de los casos aquí estudiados para comprobar la incidencia del TBL y el desarrollo comunitario para la sostenibilidad o la resiliencia socio-ecológica (Ruiz-Ballesteros, 2011; Ruiz-Ballesteros y Gual, 2012).

Nuestros análisis nos animan a pensar que la vinculación entre comunidad y TBL debe ser considerada de manera recursiva y nunca como una relación causal en un solo sentido. Esto es: no cabe solo considerar las formas de funcionamiento comunitario como un requisito necesario (aunque no suficiente) para el desarrollo del TBL, sino que debe también contemplarse que el propio desarrollo de actividades turísticas lideradas desde lo local podría contribuir a construir comunidad. Ello depende, obviamente, del contexto socio-cultural y del modo en que se desarrolle el TBL, de lo cual nuestros casos de estudio dan buena cuenta. Si el turismo se considera una actividad estratégica para la sociedad local y sus recursos se gestionan en mayor o menor grado de forma colectiva, 
entonces el propio desarrollo de la actividad turística debería contribuir — según la definición que aquí proponemos- al desarrollo de pautas comunitarias. Por su parte, una comunidad sólida - con un alto nivel de interacción social y acción colectiva sobre recursos estratégicos- facilitaría, teóricamente, el desarrollo del TBL como otro ámbito más de actividad común.

Hasta ahora hemos sido capaces de madurar una conceptualización más o menos precisa y operativa de la noción de comunidad. Los casos de Agua Blanca, Floreana o Alájar, por muy diversos que sean -y por eso han sido elegidos- nos han mostrado, a través de una exposición consciente y peligrosamente sucinta, las luces que esta perspectiva metodológica arroja sobre el TBL. Pero el viaje no ha terminado, solo ha hecho comenzar, falta dilucidar todavía qué sombras proyecta esta misma perspectiva sobre nuestra comprensión. 


\section{REFERENCIAS BIBLIOGRÁFICAS}

Agrawal, A. y Gibson, C.C. (1999) "Enchantment and Disenchantment: The Role of Community in Natural Resource Conservation". World Development 27 (4), pp. 629-649. Andrada, J.; Cantero, P. y Ruiz Ballesteros, E. (2010) Habitar Galápagos. Encrucijada de naturaleza y cultura. Quito: Presidencia de la República del Ecuador / Universidad de Cuenca.

Andrada, J.; Cantero, P.A. y Ruiz-Ballesteros, E. (e/p) Floreana. Islamundo en Galápagos. Quito: Abya-Yala.

Bauman, Z. (2001) Community. Seeking Safety in an Insecure World. London: Polity Press. Blackstock, K. (2005) "A critical look at community based tourism". Community Development Journal 40(1), pp. 39-49.

Brondizio, E.S.; Ostrom, E. and Young, O.R. (2009) "Connectivity and the governance of multilevel social-ecological systems: the role of social capital”. Annual Review of Environmental Resources 34, pp. 253-278.

Chaiklin, S. y Lave, J. (editores) (1993) Understanding Practice. Perspective on activity and context. Cambrige: Cambringe University Press.

Chevalier, M. (1981) “Les phénomènes néo-ruraux”. Espace géographique1(1), pp. 175191.

Cohen, A. (1985) The symbolic construction of the community. London: Routledge.

De Certau, M. (1990) L'Invention du Quotidien I. Arts de Faire. Paris: Gallimard.

Godbout, J.T. (2013) Le don, la dette et la indentité. Paris: Le bord de l'eau.

Gosnell, H., Abrams, J. (2011) "Amenity migration: diverse conceptualizations of drivers, socio -economic dimensions, and emerging challenges". GeoJournal 76(4), pp. 303 -322.

Hernández, M y Ruiz Ballesteros, E. (2011) “Etnogénesis como práctica. Arqueología y turismo en el pueblo Manta (Ecuador)." AIBR Revista de Antropología Iberoamericana 6(2), pp. 159-192.

Iorio, M., \& Corsale, A. (2014) "Community-based tourism and networking: Viscri, Romania”. Journal of Sustainable Tourism 22 (2), pp. 234-255.

Magis, K. (2010) "Community resilience: An indicator of social sustainability". Society and Natural Resources 23, pp. 401-416.

Matarrita-Cascante, D.; Brennan, M.A. \& Luloff, A. E. (2010) "Community agency and sustainable tourism development: the case of La Fortuna, Costa Rica”. Journal of Sustainable Tourism 18 (6), pp. 735-756. 
McEwan, C.; M. I. Silva, y C. Hudson (2006) "Using the past to forge the future. The genesis of the community site museum at Agua Blanca, Ecuador". En Helaine Silverman Archaeological Site Museums in Latin America. University Press of Florida, pp. 187-216. Moss, L. ed. (2006) The Amenity migrants. Seeking and sustaining mountains and their cultures. Cabi.

Nogué i Font, J. (1988) “El fenómeno neorrural”. Agricultura y sociedad 47, pp. 145-175.

Redfield, R. (1960) The little community and Peasant Society and Culture. Chicago: University of Chicago Press.

Ruiz-Ballesteros, E. (2009) Agua Blanca. Comunidad y turismo en el Pacífico ecuatorial. Quito:Abya-yala.

Ruiz-Ballesteros, E. (2011) "Socio-ecological resilience and community-based tourism. An approach from Agua Blanca, Ecuador”. Tourism Management 32, pp. 655-666.

Ruiz-Ballesteros, E. (2012) "La vigencia de la comunidad. Prácticas para navegar en la globalización desde la periferia andina”. Chungara. Revista Chilena de Antropología 44, pp. 419-433.

Ruiz-Ballesteros, E. y Brondizio, E.S. (2013) "Building negotiated agreement: The emergence of community based tourism in Floreana (Galapagos Islands)". Human Organization 72(4), pp. 323-335.

Ruiz-Ballesteros, E. y Cáceres-Feria, R. (e/r) "Community-based tourism, outsider residents and community building. Reflections from Southwestern Spain.”

Ruiz-Ballesteros, E. y Cantero Martín, P. (2011) "Entre Darwin, La Baronesa y el Cucuve. El Desarrollo del Turismo de Base Local en Floreana (Galápagos)”. En LL. Prats y A. Santana (coords.) Turismo y patrimonio, entramados narrativos. La Laguna: Pasos, pp. 71-85.

Ruiz-Ballesteros, E. y Gual, M.A. (2012) "The emergence of new commons. Community and multi-level governance in the Ecuadorian coast". Human Ecology 40, pp. 847-862.

Ruiz-Ballesteros, E. y Solis Carrión, D. (coords.) (2007) Turismo comunitario en Ecuador. Desarrollo y Sostenibilidad Social. Quito: Abya-Yala.

Ruiz-Ballesteros, E.; Hernández, M.; Coca, A.; Cantero, P. y del Campo, A. (2008) "Turismo comunitario en Ecuador. Comprendiendo el community-based tourism desde la comunidad". Pasos. Revista de turismo y patrimonio cultural 6(3), pp. 399-418.

Temple, D. (2003a) Teoría de la Reciprocidad (tres tomos). La Paz : Padep-gtz.

Temple, D. (2003b) Las Estructuras Elementales de la Reciprocidad. La Paz: TARI / Plural editores. 
Temple, D. y M. Chabal (1995) La Reciprocité et la Naissance des Valeurs Humaines. Paris: L'Harmattan.

Wilkinson, K. P. (1991)The community in rural America. Middletown, Wisconsin: Social Ecology Press. 